\title{
The Feedback Mechanism of Carbon Emission Reduction in Power Industry of Delayed Systems
}

\author{
Xiaobao Yu, ${ }^{1}$ Zhongfu Tan, ${ }^{1,2}$ Yuxie Zhang, ${ }^{1}$ Daoxin Peng, ${ }^{3}$ and Hui Xia ${ }^{4}$ \\ ${ }^{1}$ North China Electric Power University, Beijing, China \\ ${ }^{2}$ Yanian University, Shaanxi, China \\ ${ }^{3}$ China Southern Power Grid, Guangdong, China \\ ${ }^{4}$ State Grid Cangzhou Company, Hebei, China \\ Correspondence should be addressed to Zhongfu Tan; tanzhongfubeijing@126.com
}

Received 22 July 2017; Revised 12 October 2017; Accepted 19 October 2017; Published 10 December 2017

Academic Editor: Libor Pekař

Copyright (c) 2017 Xiaobao Yu et al. This is an open access article distributed under the Creative Commons Attribution License, which permits unrestricted use, distribution, and reproduction in any medium, provided the original work is properly cited.

Carbon emissions of power industry in China have accounted for more than half of the total emissions. How to decrease them is important for realizing carbon emission reduction. This paper proposes a carbon market feedback mechanism to power market, comprehensively considering the influence of generation structure, carbon intension, and technological progress on carbon emission reduction in power industry, and builds a potential model based on dynamic system. Operation system results show that the increasing trend of carbon emission can be controlled effectively but always with a lag. At the same time, sensitivity analysis results show that carbon emission reduction can be better realized by adjusting power structure and improving technological level; the former can reduce $32 \%$ and the latter can reduce $60 \%$ at most.

\section{Introduction}

In the 21st century, climate change has been one of the most serious problems; carbon dioxide, discharged by fossil fuel combustion, plays the main role in causing global greenhouse effect, in which discharge by thermal power accounts for more than half of the total emissions. Facing increasing environmental costs, environmental pollution treatment simply depending on administrative control lacks persistence [1]. Greenhouse gas emission reduction needs close international cooperation because of its wide scope, so environmental problems can be solved effectively by market mechanism [24].

In the research of controlling carbon dioxide emissions through market mechanism, international and domestic academics have made some valuable achievements. Emissions trading is an effective measure to promote carbon emission reduction. The theory of emissions trading comes from the "Pigovian Tax." Pigou, who is welfare economist, advocates punitive emissions or rewards for emission-controlled enterprises, which could control pollution and protect the environment more effectively [5]. The pioneering research in the field of air pollution control, made by Croker, further promotes the development of emissions trade theory [6]. Initial carbon emission allocation system, proposed by Hahn, is an important mechanism, which will affect transactional efficiency under imperfect competition [7]. Further researches show that the initial allocation will affect enterprise's financial burden and competitiveness, and the key factors that affect competitiveness include energy intensity, emissions reduction technology, and market demand elasticity $[8,9]$.

China's research on carbon emission reduction mechanism is slightly later than other countries. From the perspective of China's carbon market, it is appropriate to adopt an allocation method at present, which is free allocation as the main and paid quotas for the auxiliary [10, 11]. Changsheng et al. modeled a two-stage dynamic game, taking two typical iron and steel enterprises as research object, and investigated the effects of unified carbon tax and differential carbon tax on reduction cost, social economic benefit, and enterprise competitiveness [12]. Chen and Teng developed an international cooperation carbon reduction mechanism, which can deal with perfect competition and monopoly carbon market 
structure [13]. Wu et al. examined $\mathrm{CO}_{2}$ emission efficiency and productivity in 286 Chinese cities under different production scenarios using a nonradial directional distance function approach and found that total-factor emission efficiency varies considerably across regional and different-sized city groups [14]. Wong et al. examined various energy-related carbon dioxide $\left(\mathrm{CO}_{2}\right)$ reduction measures and demonstrated that the influence of users on $\mathrm{CO}_{2}$ reduction is significant and compatible with the influence of water-efficient showerheads [15].

This paper puts forward a set of feedback mechanisms, which applies to the status quo of domestic power industry carbon emissions. Through the carbon market feedback to the electricity market, it restrains carbon emissions growth in power industry. With system dynamics as a platform, this paper builds carbon emission reduction potential model in power industry, sets related parameters according to different scenarios, takes power structure, carbon intensity, and technology progress for sensitivity analysis, and verifies the feasibility and effectiveness of the feedback mechanism according to the operation results.

\section{Materials and Methods}

2.1. Carbon Market Feedback Structure. China's per unit electricity carbon emission is 1.3-1.4 times that of the United States; in the meantime, the power industry is one of the larger proportion industries in total carbon emissions. How to effectively control carbon emission is the key point for future time. Exploring carbon reduction potential and realization path in power industry is the critical path in the process of developing low carbon economy in our country [16-19]. Considering the affinity between carbon market and power market, this paper builds a carbon market feedback structure to power market through controlling important factors in carbon market; it affects the carbon emissions in power market adversely. The feedback structure mainly includes two feedback loops, which was shown in Figure 1.

Loop 1. The growth of thermal power generation increases coal consumption and pollution emissions, reduces the opportunities and income, which comes from power suppliers to participate in the emissions reduction trading, thus improving carbon emission trading cost, reduces the proportion of thermal power generation relatively, and reduces thermal power generation, which constitutes the negative feedback loop in carbon emission trading link.

Loop 2. The growth of power consumption increases thermal power generation and then increases carbon emission in power industry, which results in an increase of carbon emissions throughout the market. Under the condition that GDP growth remains the same, carbon emissions intensity was relatively increased and power consumption growth slows down and thus reduces electricity consumption, which constitutes the negative feedback loop in carbon emission intensity control link.

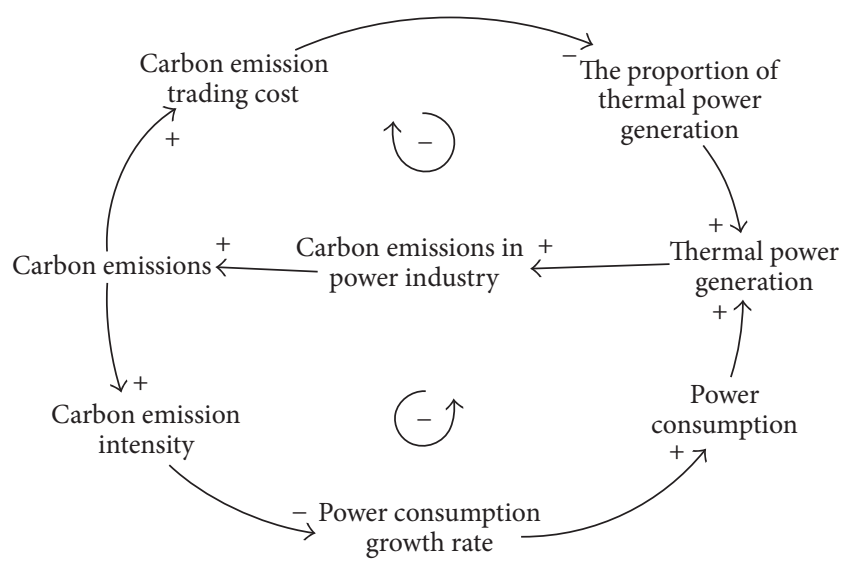

Figure 1: System basic variable causal loop diagram.

2.2. Carbon Reduction Potential System Dynamics Model. According to the analysis of system structure and the modeling principle of system dynamics, the software Vensim was used to draw carbon reduction potential analysis model in power industry [20-23]. The model includes power generation subsystem and carbon emissions subsystem; the former is divided into two modules, power demand and power generation structure, and the latter is also divided into two modules, carbon emissions trading and carbon emission intensity control.

Modeling language adopts DYNAMO; in the equation, $L$ expresses state variable, $R$ expresses rate variable, $A$ expresses auxiliary variable, and $D T$ expresses time step between moment $J$ and moment $K$.

2.2.1. Power Demand Module. The system dynamic model of power demand module was shown at the bottom-right part in Figure 2. Power demand, affected by social economic level, is the main factor to define generation, which in turn affects the power generation coal consumptions and emissions. This module calculates power demand on the basis of accumulating GDP by industry [24, 25]. In the meantime, considering the consumer power sensitivity to price changes, the energy price elasticity coefficient was introduced to calculate power demand changes caused by price changes, expressed in the following formulas:

$$
\begin{aligned}
& T_{P} . J K=\operatorname{INTEG}\left(D *\left(P_{B} . J-P_{D} \cdot J\right), T_{P} \cdot J\right) \\
& P_{B} \cdot K=T_{P} \cdot K * \xi_{B} \\
& P_{D} \cdot K=T_{P} \cdot K * \xi_{D} \\
& \text { GDP.JK } \\
& =\operatorname{INTEG}(D *(\Delta \text { GDP. } K-\Delta \text { GDP.J }), \text { GDP. } J) \\
& \Delta \mathrm{GDP} . K=\mathrm{GDP} . J * \alpha \\
& P_{\mathrm{GDP}} \cdot K=\frac{\mathrm{GDP} \cdot K}{T_{P} \cdot K} \\
& \beta=\beta_{1} P_{\mathrm{GDP}} \cdot K+\beta_{2} * \alpha+\beta_{3} * \chi+\varepsilon
\end{aligned}
$$




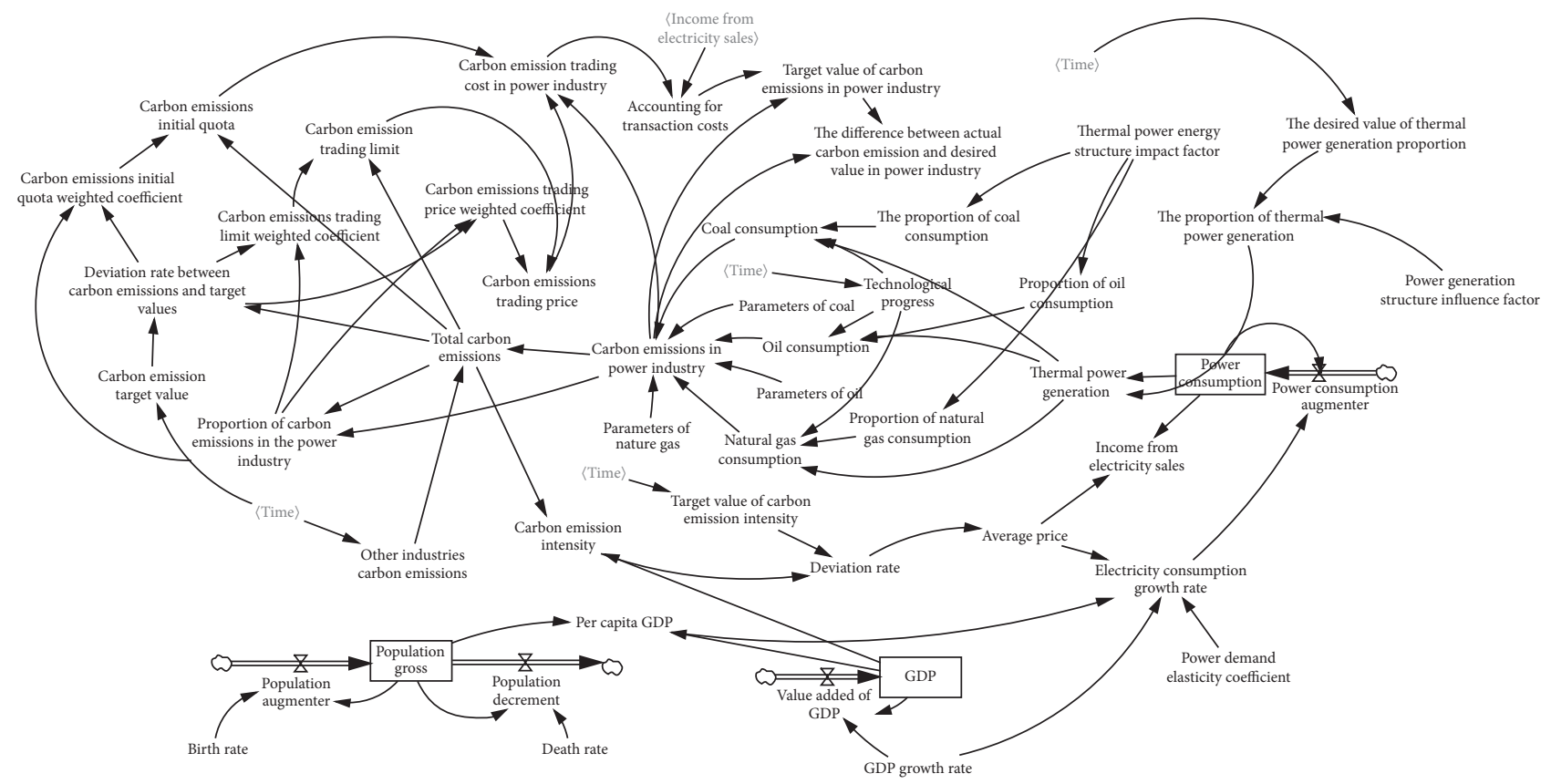

FIGURE 2: Carbon reduction potential system dynamics model in power industry.

$$
\begin{aligned}
& \Delta C_{E} \cdot K=C_{E} \cdot J *(1+\beta) \\
& C_{E} \cdot K=\operatorname{INTEG}\left(D *\left(\Delta C_{E} \cdot K-\Delta C_{E} \cdot J\right), C_{E} \cdot J\right),
\end{aligned}
$$

where $T_{P}$ expresses population gross;.$K$ expresses $K$ time node; .J expresses $J$ time node; $D$ expresses time period from $J$ to $K ; P_{B}$ expresses population augmenter; $\xi_{B}$ expresses birth rate; $P_{D}$ expresses population decrement; $\xi_{D}$ expresses death rate; GDP expresses gross domestic product; $\Delta$ GDP expresses value added of gross domestic product; $\alpha$ expresses GDP growth rate; $P_{\mathrm{GDP}}$ expresses per capita GDP; $\beta$ expresses electricity consumption growth rate; $\beta_{1}, \beta_{2}, \beta_{3}$, respectively, express the fitting parameters of per capita GDP, GDP growth rate, and power demand elasticity; $\chi$ expresses power demand elasticity coefficient; $\varepsilon$ expresses error coefficient of fitting function; $\Delta C_{E}$ expresses power consumption augmenter; $C_{E}$ expresses power consumption.

2.2.2. Power Generation Structure Module. The system dynamic model of power generation structure module was shown at the upper-right part in Figure 2. This paper mainly researches the carbon reduction potential in power industry, so only the thermal power generating part was studied. This module introduces power generation structure impact factors to represent the desired thermal power ratio; for thermal power generation energy structure, thermal power energy structure impact factors were used to express the proportion of each fuel.

$$
\begin{gathered}
P_{E} \cdot K=C_{E} \cdot K * \phi \\
\delta_{C}=\eta * \kappa_{1} \\
\delta_{O}=\eta * \kappa_{2}
\end{gathered}
$$

$$
\begin{aligned}
\delta_{G} & =\eta * \kappa_{3} \\
T_{C} \cdot K & =P_{E} \cdot K * \delta_{C} \\
T_{O} \cdot K & =P_{E} \cdot K * \delta_{O} \\
T_{G} \cdot K & =P_{E} \cdot K * \delta_{G} \\
\phi \cdot K & =\operatorname{DELAY}\left(o_{\phi} \cdot K-\rho_{E_{P}} \cdot J * \gamma, D T\right),
\end{aligned}
$$

where $P_{E}$ expresses thermal power generation; $\phi$ expresses the proportion of thermal power generation; $\delta_{C}$ expresses the proportion of coal consumption; $\delta_{O}$ expresses the proportion of oil consumption; $\delta_{G}$ expresses the proportion of natural gas consumption; $\eta$ expresses power generation structure impact factors; $\kappa_{1}, \kappa_{2}, \kappa_{3}$, respectively, express the proportion parameters of three kinds of energy; $T_{C}$ expresses coal consumption; $T_{O}$ expresses oil consumption; $T_{G}$ expresses natural gas consumption; $o_{\phi}$ expresses the desired value of thermal power generation proportion; $\rho_{E_{P}}$ expresses the difference between actual carbon emission and desired value in power industry; $\gamma$ expresses delay coefficient; $\operatorname{DELAY} 1(f, t)$ is the delay function of system dynamics, $f$ is the delay value, and $t$ is delay time. In tape (17), considering the lag nature of enacting the actual proportion of thermal power generation, the delay link was set in the power generation structure model; the delay time is the interval from moment $J$ to moment $K$.

2.2.3. Carbon Emissions Trading Module. The system dynamic model of carbon emissions trading module was shown at the upper-left part in Figure 2, which mainly studies the influence of carbon emissions on the carbon emissions trading market, including carbon emissions initial quota, 
transaction amount, and transaction price, expressed in the following formulas:

$$
\begin{aligned}
E_{C} \cdot K & =T_{C} \cdot K * \mu_{C}+T_{O} \cdot K * \mu_{O}+T_{G} \cdot K * \mu_{G} \\
\Delta E_{C} \cdot K & =E_{C} \cdot K-E_{C} \cdot J \\
\Delta I_{C} \cdot K & =\operatorname{DELAY}\left(\Delta E_{C} \cdot J+\Delta E_{U} \cdot J, D T\right) \\
I_{C} \cdot K & =\operatorname{INTEG}\left(\Delta I_{C} \cdot K, I_{C}, J\right),
\end{aligned}
$$

where $E_{C}$ expresses carbon emissions in power industry; $\mu_{C}, \mu_{O}, \mu_{G}$, respectively, express the carbon emissions coefficient of three kinds of energy; $\Delta E_{C}$ expresses value added of carbon emissions in power industry; $\Delta I_{C}$ expresses value added of industrial carbon emissions; $\Delta E_{U}$ expresses value added of other industries carbon emissions; $I_{C}$ expresses total carbon emissions.

Because of the delay when counting up the value added of carbon emissions, a delay link needs to be set; the delay time is the interval from moment $J$ to moment $K$. The value added of other industries was forecasted according to history values.

In order to better study the influence of carbon emissions on the carbon emissions trading market, this paper sets a desired value of carbon emissions and, according to the deviation rate between the carbon emission actual value and the carbon emission target value, calculates the carbon emissions initial quota weighted coefficient, the carbon emissions trading limit weighted coefficient, and the carbon emissions trading price weighted coefficient. Because of the deviation rate, delay link was introduced.

$$
\begin{aligned}
& \rho_{E_{P}} \cdot K=\operatorname{DELAY}\left(I_{C} \cdot K-O_{I_{C}} \cdot J, D T\right) \\
& \omega_{1} \cdot K=\frac{\rho_{E_{P}}}{E_{P}} \cdot K * \sigma_{1} \\
& \omega_{2} \cdot K=\frac{\rho_{E_{P}}}{E_{P}} \cdot K * \sigma_{2} \\
& \omega_{3} \cdot K=\frac{\rho_{E_{P}}}{E_{P}} \cdot K * \sigma_{3}
\end{aligned}
$$

where $O_{I_{C}}$ expresses the carbon emission target value; $\omega_{1}$ expresses the carbon emissions initial quota weighted coefficient; $\omega_{2}$ expresses the carbon emissions trading limit weighted coefficient; $\omega_{3}$ expresses the carbon emissions trading price weighted coefficient; $\sigma_{1}, \sigma_{2}, \sigma_{3}$ express corrected parameter of three weighted coefficients.

One thing to note is that these weighting coefficients refer in particular to the distributable initial quota of power industry, tradable credits of power industry, and trading price of power industry.

$$
\begin{aligned}
& E_{\mathrm{QC}} \cdot K=I_{C} \cdot K * \omega_{1} \\
& E_{\mathrm{TRC}} \cdot K=I_{C} \cdot K * \omega_{2} \\
& E_{P C} \cdot K=I_{C} \cdot K * \omega_{3} *\left(1+\vartheta * \frac{E_{\mathrm{TRC}}}{I_{C}}\right)
\end{aligned}
$$

$$
\begin{aligned}
& C_{\mathrm{EC}} \cdot K=\left(E_{C} \cdot K-E_{\mathrm{QC}} \cdot K\right) * E_{P C} \cdot K \\
& O_{\mathrm{EC}} \cdot K=E_{C} \cdot K * \text { IF_THEN_ELSE }\left(\frac{C_{\mathrm{EC}} \cdot K-C_{\mathrm{EC}} \cdot J}{C_{\mathrm{EC}} \cdot J}\right. \\
& \quad \leq 0.05,1.05,0.95) \\
& \rho_{E_{\mathrm{C}}} \cdot K=E_{C} \cdot K-O_{\mathrm{EC}} \cdot K,
\end{aligned}
$$

where $E_{\mathrm{QC}}$ expresses the carbon emissions initial quota; $E_{\mathrm{TRC}}$ expresses the carbon emission trading limit; $C_{\mathrm{EC}}$ expresses the carbon emission trading cost in power industry; $O_{\mathrm{EC}}$ expresses the difference between the carbon emission actual value and the carbon emission target value in power industry.

IF THEN ELSE $(a, b, c)$ is the conditional function of system dynamics, $a$ expresses condition, $b$ expresses variable value when the condition is satisfied, and $c$ expresses variable value when the condition is not satisfied. Tape (24) shows that when the transaction variable cost ratio is not greater than $5 \%$, carbon emissions in power industry will increase, setting coefficient as 1.05; if the ratio is greater than $1 \%$, carbon emission in power industry will decrease, setting coefficient as 0.95 . This is because when the change of carbon emission trading cost is very small, the power industry will not consider the carbon trading cost; when the change ratio is greater than $5 \%$, the power industry will consider reducing carbon trading cost, thus reducing carbon emissions and thermal power generation.

2.2.4. Carbon Emission Intensity Control Module. The system dynamic model of carbon emissions intensity module was shown at the center part in Figure 2, which mainly studies the fact that carbon emissions affect carbon emission intensity and, in turn, affect power demand growth rate. Carbon emission intensity desired value represents expected intensity through comparing the difference between actual value and desired value to analyze the change of power demand growth rate; the formula is as follows:

$$
\begin{aligned}
e_{C} \cdot K & =\frac{I_{C} \cdot K}{\mathrm{GDP} \cdot K} * 100 \% \\
\xi & =\frac{e_{C} \cdot K-O_{e_{c}} \cdot K}{O_{e_{c}} \cdot K} \\
\beta . K & =\beta . J * \text { IF_THEN_ELSE }(\xi \leq 0,1,0.95),
\end{aligned}
$$

where $e_{C}$ expresses carbon emission intensity; $\xi$ expresses the deviation rate between the carbon emission intensity actual value and the carbon emission intensity desired value; $O_{e_{c}}$ expresses the carbon emission intensity desired value.

Here, changes of power consumption growth rate are revised on the basis of power consumption growth rate calculated by per capita GDP, GDP growth rate, and power demand elasticity. When the difference between carbon emission intensity actual value and the desired value is less than zero, power consumption growth rate stays the same; if the difference is greater than zero, a weight, which is 0.95 , is added to the power consumption growth rate. 
TABLE 1: Some indicators statistics from the 2003 to 2011.

\begin{tabular}{lcccc}
\hline Years & $\begin{array}{c}\text { Electricity } \\
\text { consumption growth } \\
(\%)\end{array}$ & $\begin{array}{c}\text { GDP per capita (ten } \\
\text { thousand } \\
\text { yuan/people) }\end{array}$ & $\begin{array}{c}\text { GDP growth rate } \\
(\%)\end{array}$ & $\begin{array}{c}\text { Electricity demand } \\
\text { elasticity }\end{array}$ \\
\hline 2003 & 15.30 & 1.04 & 10.00 & 1.56 \\
2004 & 15.46 & 1.23 & 10.10 & 1.52 \\
2005 & 13.90 & 1.40 & 11.30 & 1.19 \\
2006 & 14.16 & 1.64 & 12.70 & 1.15 \\
2007 & 14.42 & 2.02 & 9.60 & 1.01 \\
2008 & 5.49 & 2.38 & 9.20 & 0.58 \\
2009 & 6.44 & 2.55 & 10.40 & 0.78 \\
2010 & 14.77 & 2.98 & 9.30 & 1.27 \\
\hline
\end{tabular}

The results show that there are significant and stable positive correlations among GDP per capita, GDP growth rate, and electricity demand elasticity.

\section{Results and Discussion}

3.1. Parameters Setting. The data of the China economy and the power industry in 2010 are taken as a benchmark in the model; the model researched effects of carbon emission reduction in electric power industry and key influencing factors in the systems from 2015 to 2050. Among them, the growth rate forecast of electricity consumption primary considered GDP per capita, GDP growth rate, and electricity demand elasticity of the three factors. Table 1 showed the domestic GDP growth, GDP per capita, electricity demand elasticity, and electricity consumption growth in China from 2003 to 2011 . On the basis of data and prediction model, in the future, Chinese power consumption growth can be expressed as

$$
Y=-12.005+0.228 X_{1}+1.101 X_{2}+10.528 X_{3},
$$

where $X_{1}$ expresses GDP per capita, $X_{2}$ expresses GDP growth rate, $X_{3}$ expresses electricity demand elasticity, and $Y$ expresses electricity consumption growth.

For the control measures of carbon market can be effectively fed back to the electricity market, this model considers the deviation between the actual carbon emission and the target value and develops some weighting coefficients, including power industry carbon emissions initial quota weighted coefficient, trade quota weighted coefficient, and carbon trading price weighted coefficient. By adjusting the weighting coefficient, the model adjusts the carbon emission target and then controls the power industry carbon emissions $[26,27]$.

(1) Initial Quotas Weighting Factor of Power Industry Carbon Emissions. Firstly, in the case without considering other factors, initial quotas weighting factor of power industry carbon emissions is formulated in accordance with the grandfather model, which is

$$
\omega_{1}=\frac{E_{C}}{I_{C}} \times 100 \% .
$$

Then, the model takes into account the goal of reducing carbon emissions to formulate a carbon emissions target; combined with the actual carbon emissions to compare, the power industry carbon emissions quotas initial weighting coefficient is adjusted based on the deviation rate, detailed as follows:

$$
\omega_{1}^{\prime}=\frac{E_{C}}{I_{C}} \times \rho_{E_{C}} \times 100 \% .
$$

(2) Power Industry Carbon Emissions Trading Credits Weighting Factor. Firstly, in the case without considering other factors, initial quotas weighting factor of power industry carbon emissions is allocated in accordance with the following formula:

$$
\omega_{2}=\frac{E_{C}}{I_{C}} \times 100 \% \times 1.1 .
$$

Then, the model takes into account the goal of reducing carbon emissions to formulate a carbon emissions target; combined with the actual carbon emissions to compare, the power industry carbon emissions trading credits weighting factor is adjusted based on the deviation rate, detailed as follows:

$$
\omega_{2}^{\prime}=\frac{E_{C}}{I_{C}} \times \rho_{E_{C}} \times 100 \% \times 1.1
$$

(3) Power Industry Carbon Emissions Trading Price Weighting Coefficients. In order to establish an effective carbon market feedback mechanism, this model takes into account the unit power generation cost of thermal power in formulating the power sector carbon emission trading price weighted coefficient and sets a ratio of $10 \%$, which can control the proportion of thermal power generation through the feedback of carbon emission trading price.

$$
\omega_{3}=\zeta \times 10 \%,
$$

where $\zeta$ represents generation cost of thermal power.

Then, the model takes into account the goal of reducing carbon emissions to develop a carbon emissions target; 
TABLE 2: Multiple scenarios parameter design.

\begin{tabular}{lccc}
\hline & $\begin{array}{c}\text { The impact factor of the power } \\
\text { structure }\end{array}$ & Carbon intensity target factor & Impact factor of technological advances \\
\hline BASE & 1 & 1 & 1 \\
CASE 1 & 0.9 & 1 & 1 \\
CASE 2 & 0.8 & 1 & 1 \\
CASE 3 & 0.7 & 1 & 1 \\
CASE 4 & 0.6 & 1 & 1 \\
CASE 5 & 1 & 0.9 & 1 \\
CASE 6 & 1 & 0.8 & 1 \\
CASE 7 & 1 & 0.7 & 1 \\
CASE 8 & 1 & 0.6 & 1 \\
CASE 9 & 1 & 1 & 0.9 \\
CASE 10 & 1 & 1 & 0.8 \\
CASE 11 & 1 & 1 & 0.7 \\
CASE 12 & 1 & 1 & 0.6 \\
\hline
\end{tabular}

combined with the actual carbon emissions to compare, power industry carbon emissions trading price weighting coefficient is adjusted based on the deviation rate, detailed as follows:

$$
\omega_{3}=\zeta \times 10 \% \times \rho_{E_{p}}
$$

(4) Multiple Scenarios Parameter Design. In order to analyze the impact of the key carbon emission reduction factors on the carbon emission reduction effect, which contains impact factor of power generation structure, carbon emission intensity target value, and technological progress, the model sets different parameter values to explore the system operating conditions in different scenarios (Table 2).

Among them, the impact factors of the power structure adjust the whole system by affecting thermal power generation ratio; then carbon emissions and carbon intensity are changed; the impact factors of carbon intensity target adjust the whole system by affecting carbon emission target; then carbon emissions of power industry were affected; impact factors of technical progress adjust the whole system by reducing coal consumption rate and other parameters; then carbon emissions of power industry were affected.

3.2. Baseline Conditions. Based on the simulation system constructed in this paper, parameters under the basic situation and data in 2010 are input; the operating system obtains relevant factors as shown in Table 3 (ten thousand tons/one hundred million yuan was abbreviated as $\mathrm{T} / \mathrm{O}$ ).

Figure 3 shows the trend situation of thermal power plants electricity generated proportion over the years; it can be seen from the figure that, in the constraints of feedback mechanisms, the proportion of thermal power plants is declining," but the rate of decline slowed; it is explained that the proportion of thermal power plants reached a stable value; feedback system regional balance shows that feedback mechanism played a role that reduces the proportion of thermal power generation effect. Figure 4 shows the carbon intensity trends over the years; the carbon intensity target value is set to help reduce carbon emissions intensity; it can be seen from Figure 4 that the intensity of carbon emission shows a trend of first increasing and then decreasing; it is explained that the construction feedback mechanism has a period of instability; after a feedback mechanism enters into the stable phase, the carbon emission intensity is declining; it is suggested that control action of feedback mechanism to carbon emissions has hysteresis quality.

Figure 5 shows the trend of electricity consumption growth over the years; the growth of power consumption also shows a trend of first increasing and then decreasing. The growth stage is due to the rapid growth of GDP, which leads to the rapid growth of electricity consumption demand. However, due to the suppression of the growth of electricity consumption by the carbon emission intensity in the feedback mechanism, this results in decreasing part of the growth rate of power consumption. Figure 6 shows the trend of power industry carbon emissions over the years; even under constraints of feedback mechanisms, carbon emissions from the power industry are still growing year after year, which is related to the growth in demand for electricity consumption.

Figure 7 shows the trend of proportion of the power industry carbon emissions over the years; the proportion of carbon emissions from the power industry experienced a trend that first increased and then decreased; the proportion of thermal power feedback mechanism leads to slowdown of coal consumption growth; the growth rate of coal consumption is constant in other industries, so proportion of the power industry carbon emissions is declining. However, due to the cleanliness of electric power, the role of electric energy replacement appears gradually, leading to a decrease of coal consumption in other industries. As a result, the proportion of carbon emissions in the power industry has been increasing. 


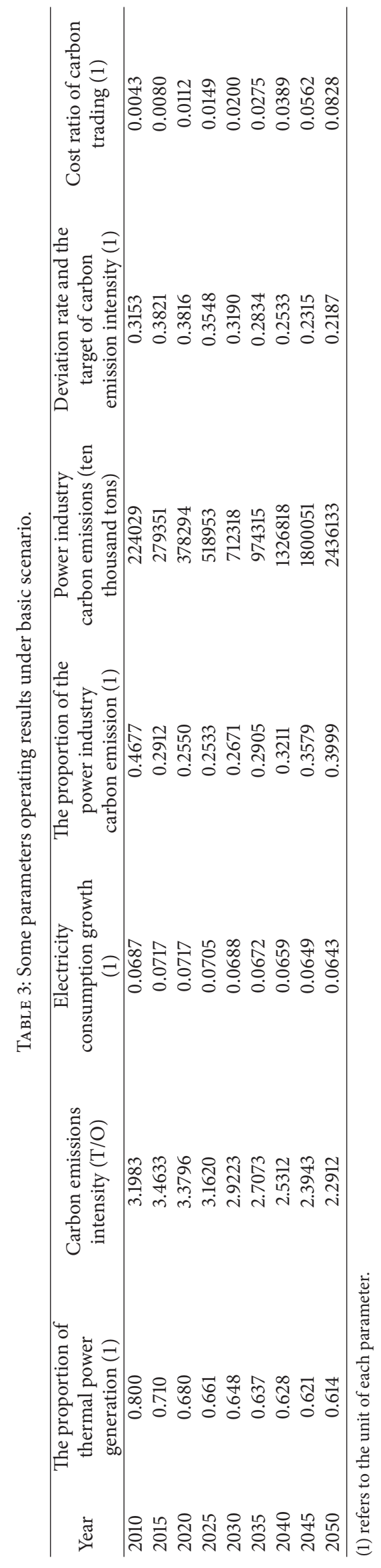




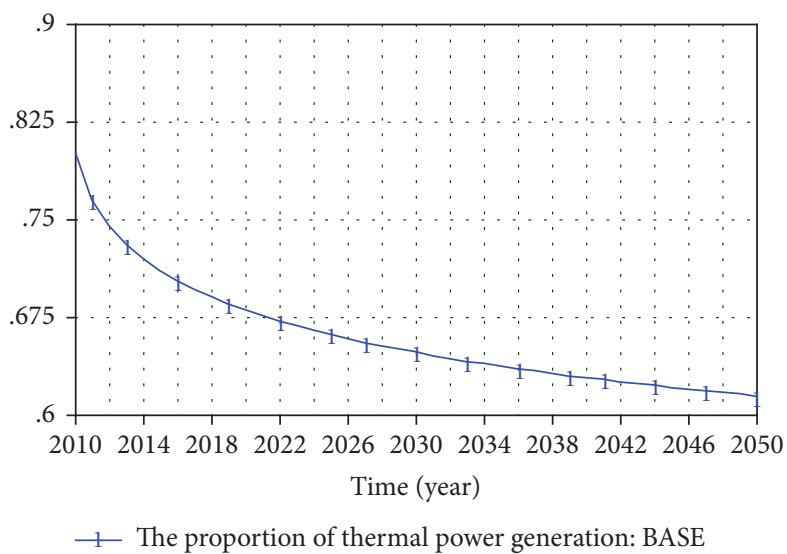

FIGURE 3: The trend of thermal power plants electricity generated proportion under the baseline scenario.

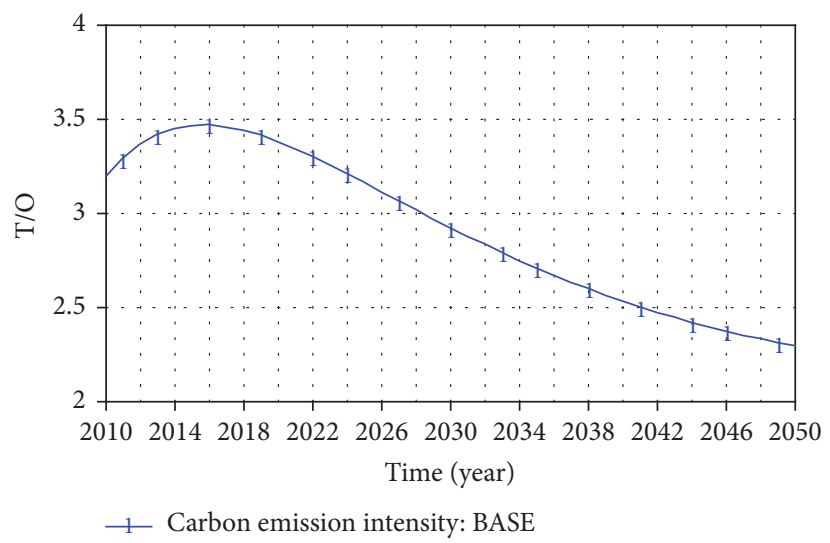

FIGURE 4: The trend of carbon intensity under the baseline scenario.

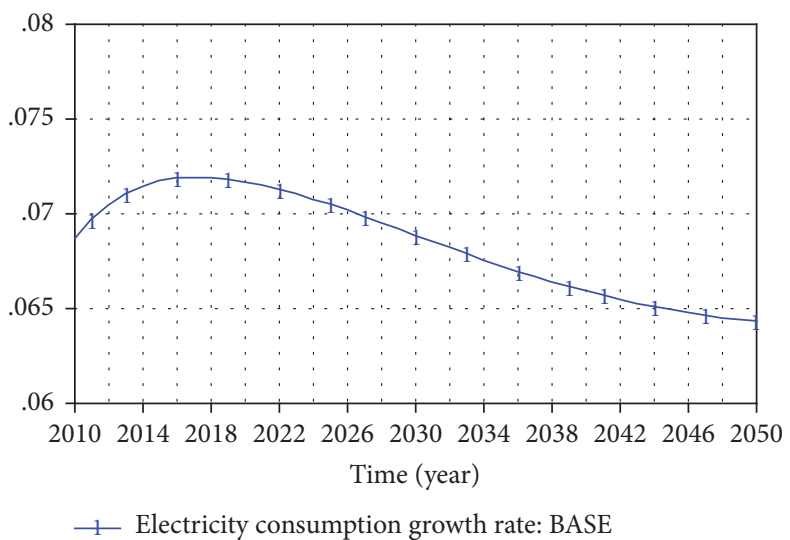

FIGURE 5: The trend of electricity consumption growth rate under the baseline scenario.

3.3. Key Elements Analysis. In order to study the key elements of carbon emission reduction in power industry, this paper performs sensitivity analysis on impact factors-generation structure, carbon intension, and technological progress and gets relevant conclusions according to the analysis results.

3.3.1. Generation Structure. According to the parameters in Table 3, different generation structure impact factors and operation systems were set for five scenarios, BASE, CASE 1, CASE 2, CASE 3, and CASE 4; relevant results were shown as attached list. Figure 8 shows the trend of ratio of thermal power generation under different parameters. With the adjustment of power generation structure, especially the feedback control of thermal power, the ratio shows a downward trend. In 2050, the ratio is 0.466 in CASE 4, which decreases by $24 \%$ compared with 0.614 in the baseline 


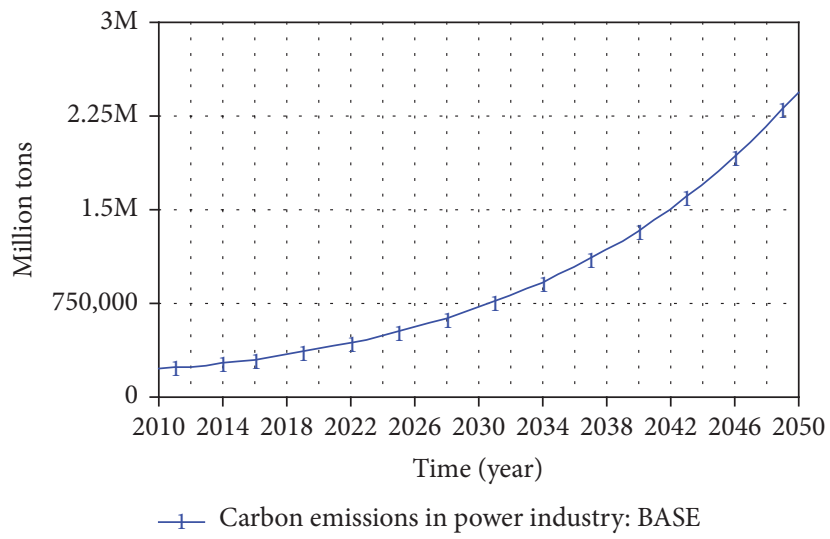

FIgURE 6: The trend of power industry carbon emissions under the baseline scenario.

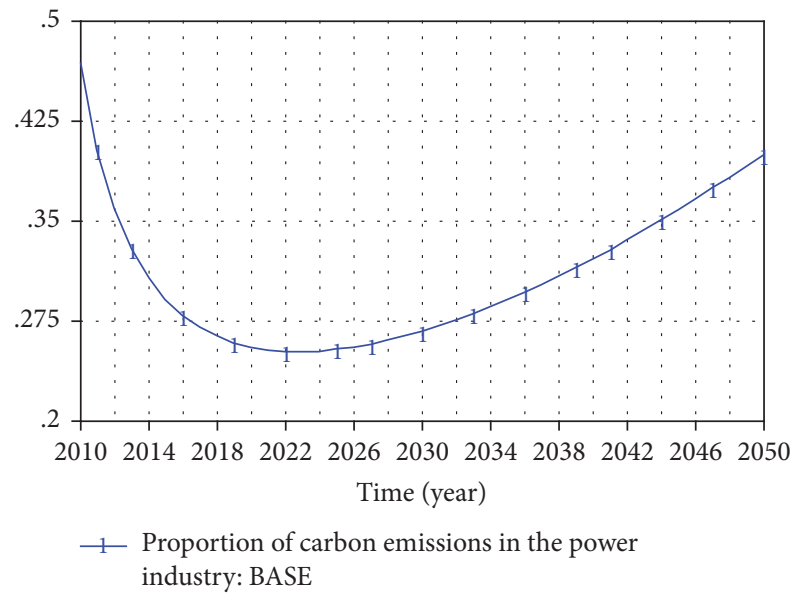

FIgURE 7: The trend of proportion of power industry carbon emissions under the baseline scenario.

scenario. The control effect on thermal power is obvious, and the growth trend of carbon emission in thermal power generation is effectively suppressed.

Figure 9 shows the trend of power consumption growth under different parameter settings. With the adjustment of power generation structure, the change in electricity consumption growth is small, which was $6.38 \%$ under CASE 4 , compared with $6.43 \%$ in the baseline scenario. This shows that the influence of power generation impact factor on it can be neglected.

Figure 10 shows the trend of carbon emissions in power industry under different parameter settings; Figure 11 shows the trend of carbon emission ratio in power industry; combined with attached list 3 and attached list 4 , it can be seen that the adjustment of generation structure has some influence on carbon emissions and emission ratio. In 2050, carbon emission is 18.16448 billion tons under CASE 4, reduces 25\%, and is lower than the baseline scenario, 24.36133 billion tons. In 2050 , the emission ratio reduces $16.8 \%$. That shows that adjusting generation structure can reduce carbon emissions, and the effect is obvious.

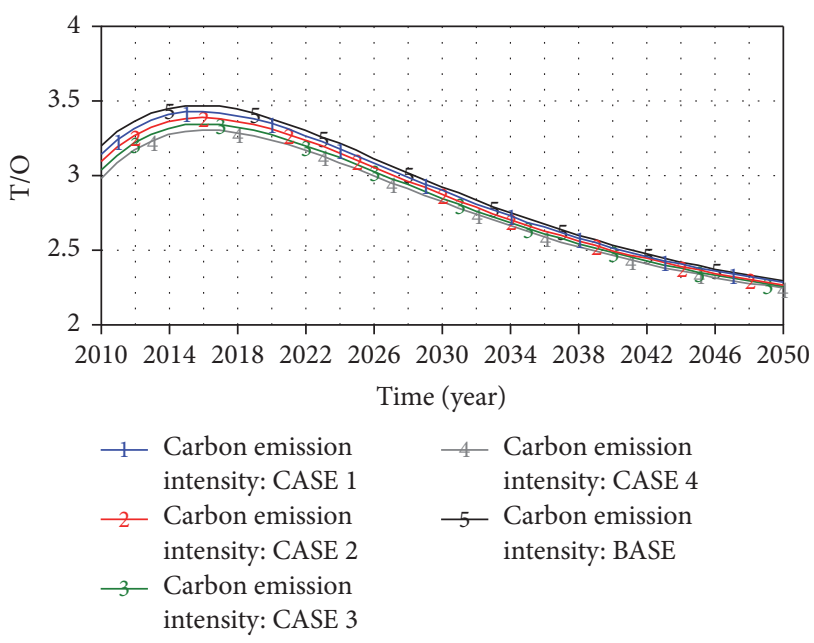

FIGURE 8: The trend of carbon emission intensity under different scenarios.

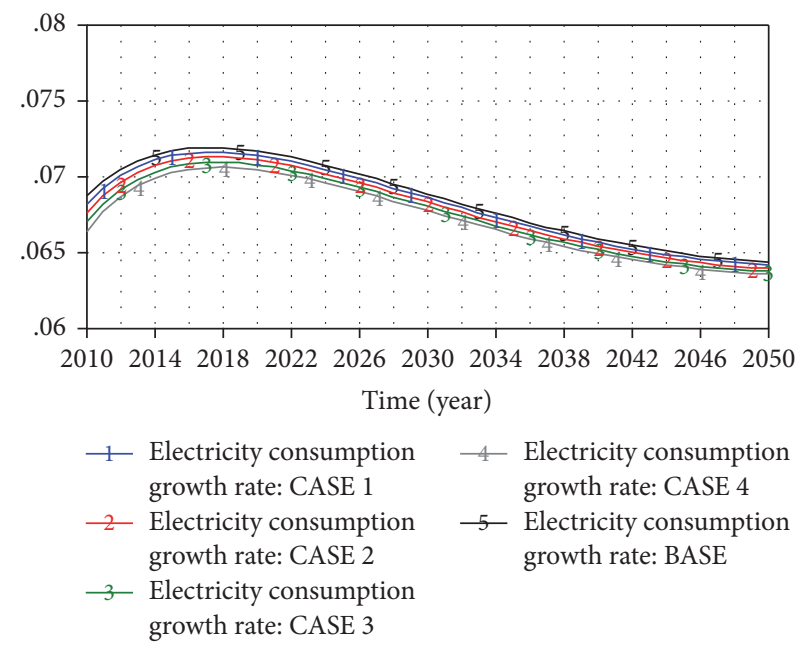

FIgURE 9: The trend of electricity consumption growth rate under different scenarios (1). The result is under generation structure. 


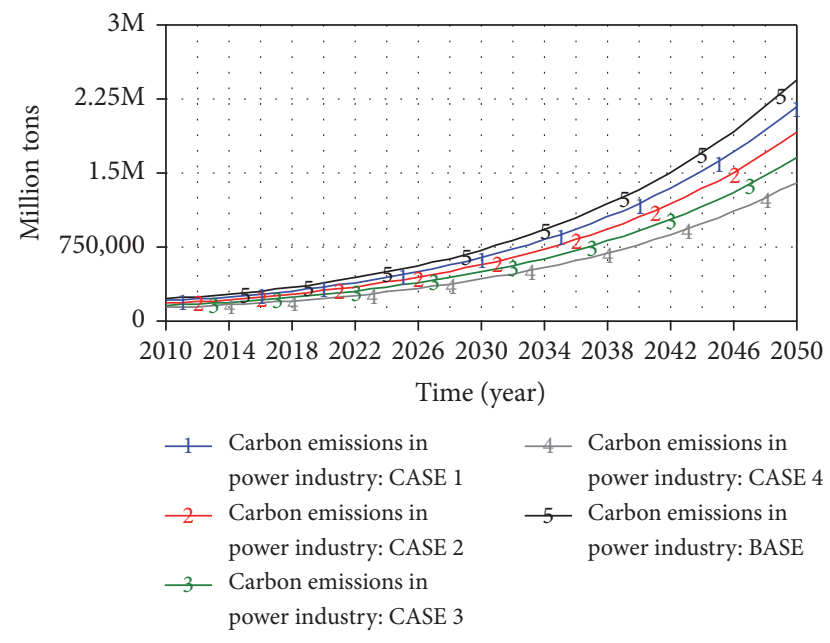

FIgURE 10: The trend of carbon emissions in power industry under different scenarios (1). The result is under generation structure.

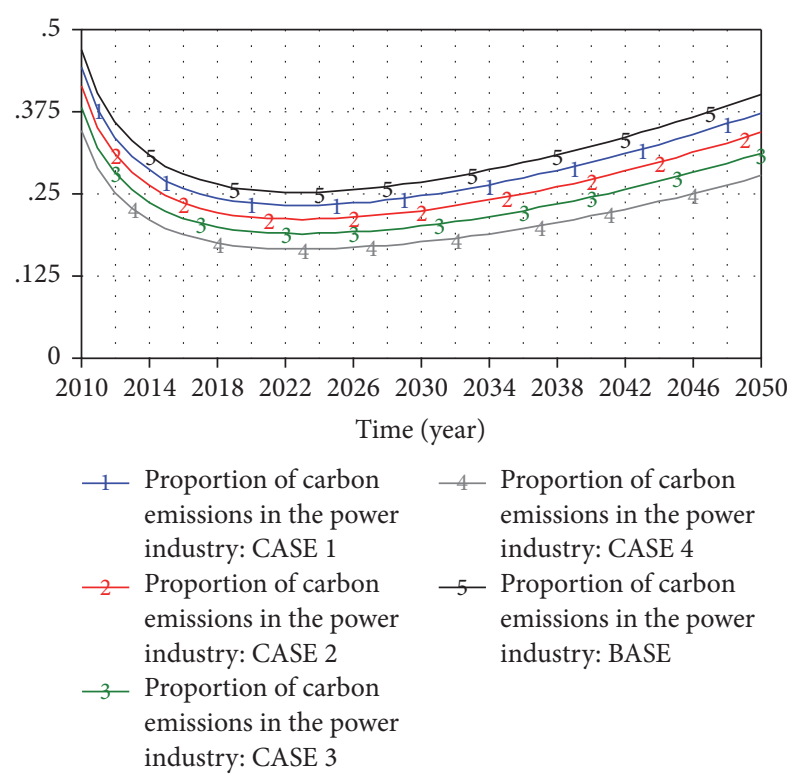

FIGURE 11: The trend of proportion of carbon emissions in power industry (1). The result is under generation structure.

3.3.2. Carbon Intension. According to the parameters in Table 3, different carbon intension impact factors and operation systems were set for five scenarios, BASE, CASE 5, CASE 6, CASE 7, and CASE 8; relevant results were shown as attached list. Figure 12 shows the trend of carbon emissions in power industry under different scenarios; combined with attached list 5, it can be seen that carbon emissions in power industry under CASE 8 in 2050 increase 60\% compared with baseline scenario. This shows that adjusting carbon intension cannot reduce carbon emission and increases it instead, which is due to the fact that the reduction of carbon intension desired value results in the increase of deviation ratio and thus influences power consumption growth and

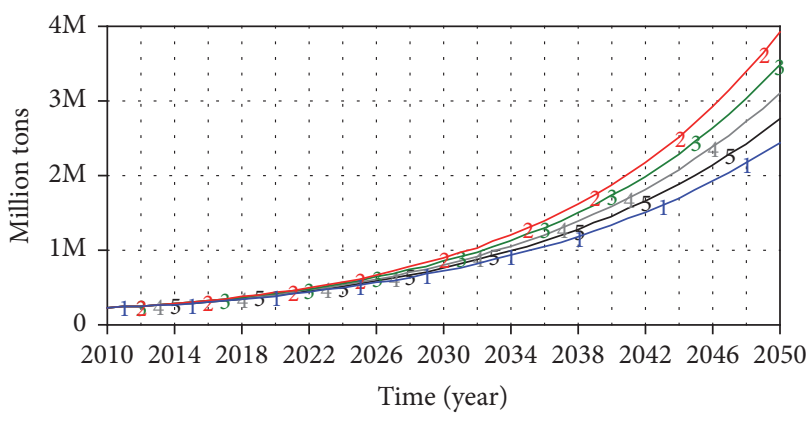

$$
\begin{aligned}
& 1 \text { Carbon emissions in } \quad 4 \text { Carbon emissions in } \\
& 2 \text { Carbon emissions in } \quad 5 \text { Carbon emissions in } \\
& \text { power industry: CASE } 8 \quad \text { power industry: CASE } 5 \\
& 3 \text { - Carbon emissions in } \\
& \text { power industry: CASE } 7
\end{aligned}
$$

FIGURE 12: The trend of carbon emissions in power industry under different scenarios (2). The result is under carbon intension.

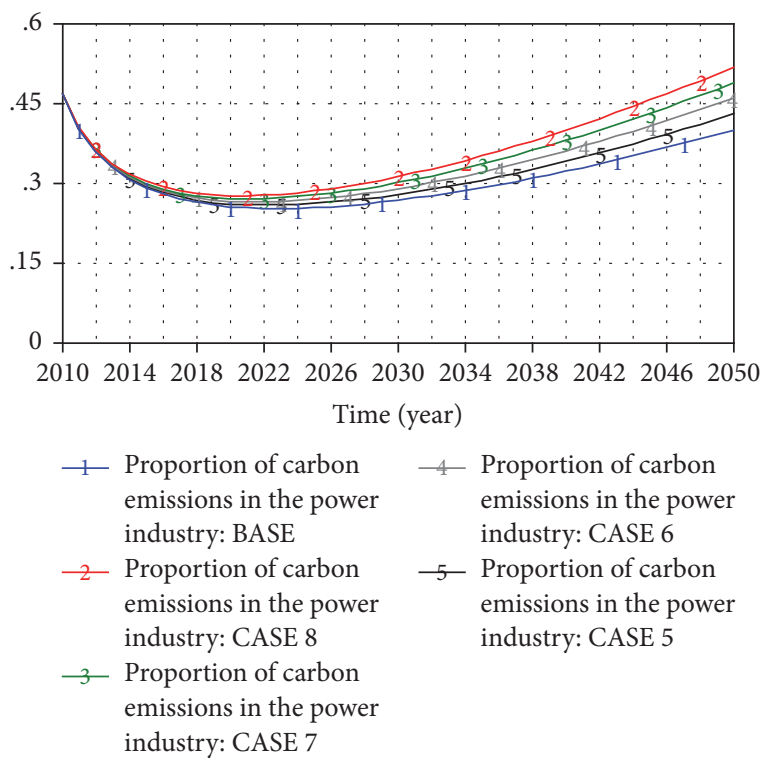

FIGURE 13: The trend of proportion of carbon emissions in power industry under different scenarios (2). The result is under carbon intension.

power demand growth and leads to the increase of carbon emissions. Figure 13 shows the trend of carbon emission ratio in power industry under different scenarios; the ratio under CASE 8 is obviously higher than baseline scenario, the same reason as carbon emission.

Figure 14 shows the trend of carbon intension under different parameter settings; combined with attached list 7, it can be seen that the adjustment of carbon intension impact factor has little influence on carbon intension. Figure 15 shows the trend of electricity consumption growth in different scenarios, which is $7.9 \%$ in CASE 8 in 2050 and decreases by $23 \%$ compared with $6.4 \%$ in the baseline scenario. This shows that adjusting carbon intension impact factor will 


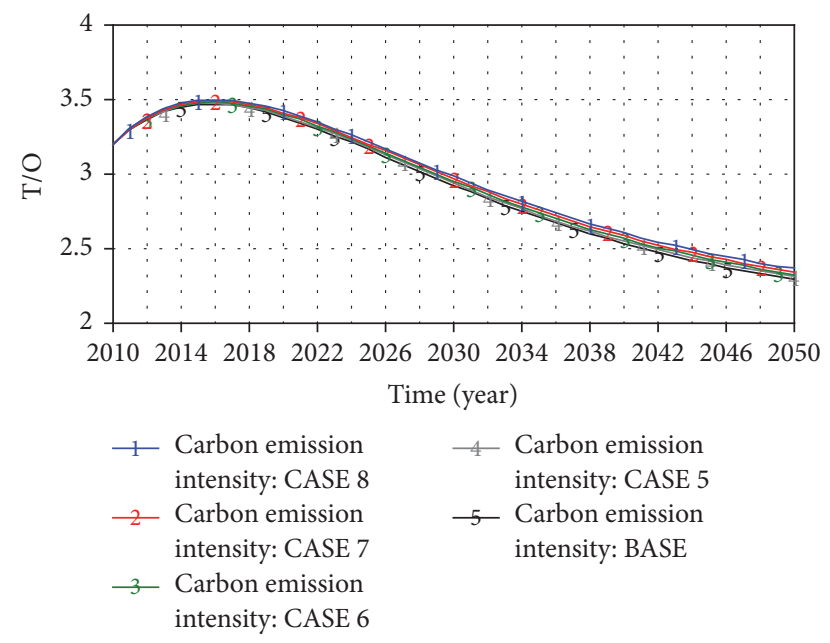

FIGURE 14: The trend of carbon emission intensity under different scenarios (1). The result is under carbon intension.

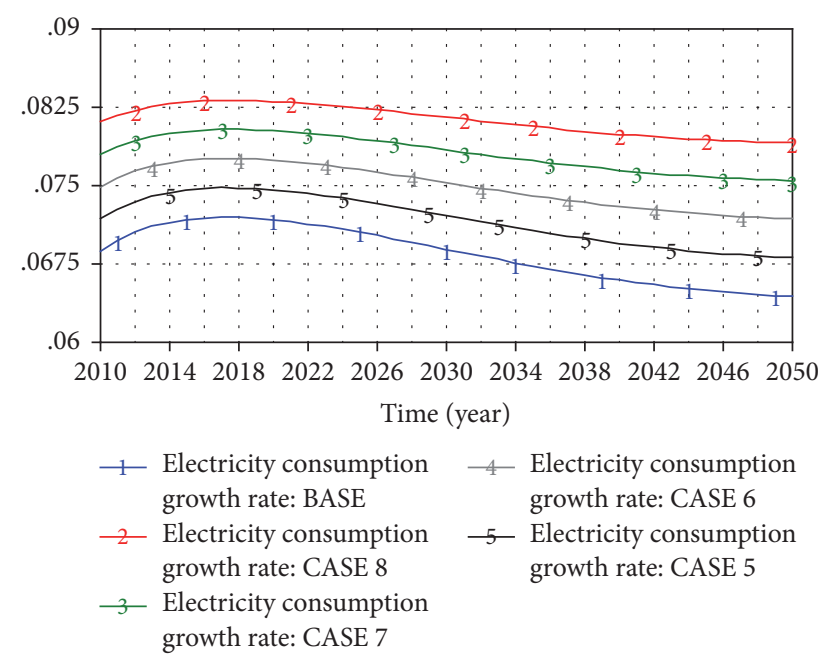

FIGURE 15: The trend of electricity consumption growth rate under different scenarios (2). The result is under carbon intension.

increase power demand and power consumption growth and thus increase carbon emissions.

3.3.3. Technological Progress. According to the parameters in Table 3, different technological progress impact factors and operation systems were set for five scenarios, BASE, CASE 9, CASE 10, CASE 11, and CASE 12; relevant results were shown as attached list. It should be noted that the starting point of technological progress is in 2025. Figure 16 shows the trend of carbon emissions in power industry under different scenarios; it can be seen that technological progress reduces carbon emissions in power industry through affecting coal consumption rate and so forth. Carbon emission under CASE 12 in 2050 reduces by $41 \%$ compared with baseline scenario; the effect is obvious. Figure 17 shows the trend of carbon emission ratio in power industry under different scenarios; combined with attached list 10 , it can be seen that the effect

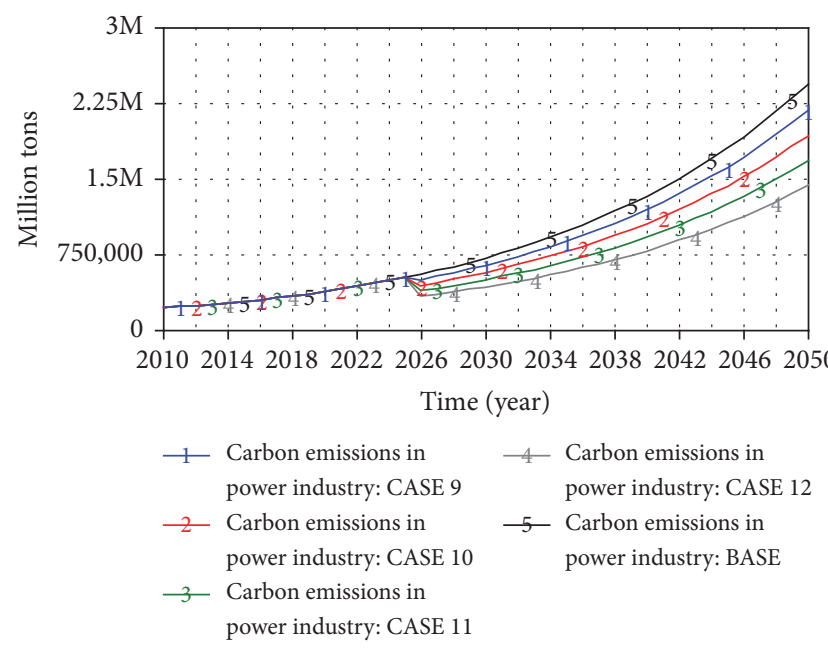

FIGURE 16: The trend of carbon emissions in power industry under different scenarios (3). The result is under technological progress.

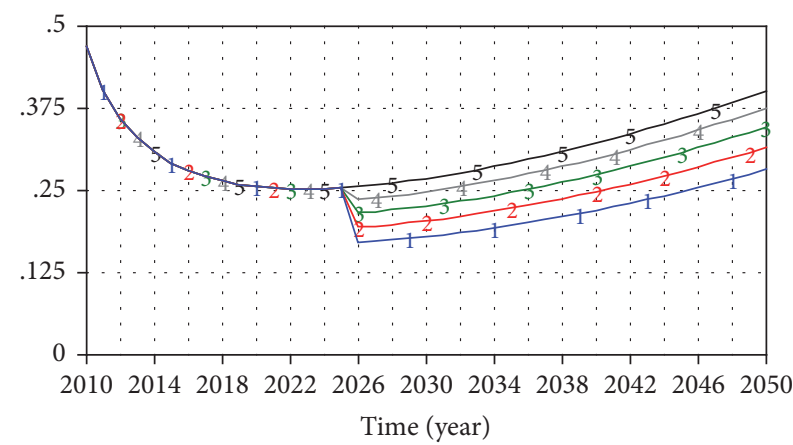

$$
\begin{array}{lr}
1-\begin{array}{l}
\text { Proportion of carbon } \\
\text { emissions in the power }
\end{array} & \begin{array}{l}
\text { Proportion of carbon } \\
\text { emissions in the power }
\end{array} \\
\text { industry: CASE } 12 & \begin{array}{l}
\text { industry: CASE } 9 \\
2-
\end{array} \\
\text { Proportion of carbon } & -5-\text { Proportion of carbon } \\
\text { emissions in the power } & \text { emissions in the power } \\
\text { industry: CASE } 11 & \text { industry: BASE } \\
3- & \\
\text { Proportion of carbon } & \\
\text { emissions in the power } & \\
\text { industry: CASE } 10 &
\end{array}
$$

Figure 17: The trend of proportion of carbon emissions in power industry under different scenarios (2). The result is under technological progress.

of reducing carbon emission ratio by technological progress is obvious, declining by up to $30 \%$.

Figure 18 shows the trend of carbon intension under different parameter settings; combined with attached list 11 , it can be seen that the adjustment of technological progress impact factor has a common influence on carbon intension; the decrease is $2 \%$. Figure 19 shows the trend of power consumption growth under different parameter settings; combined with attached list 12 , it can be seen that the adjustment of technological progress impact factor also has a common influence on power consumption growth; the range is less than $1 \%$. Therefore, under the situation that technological progress impact factor does not affect power 


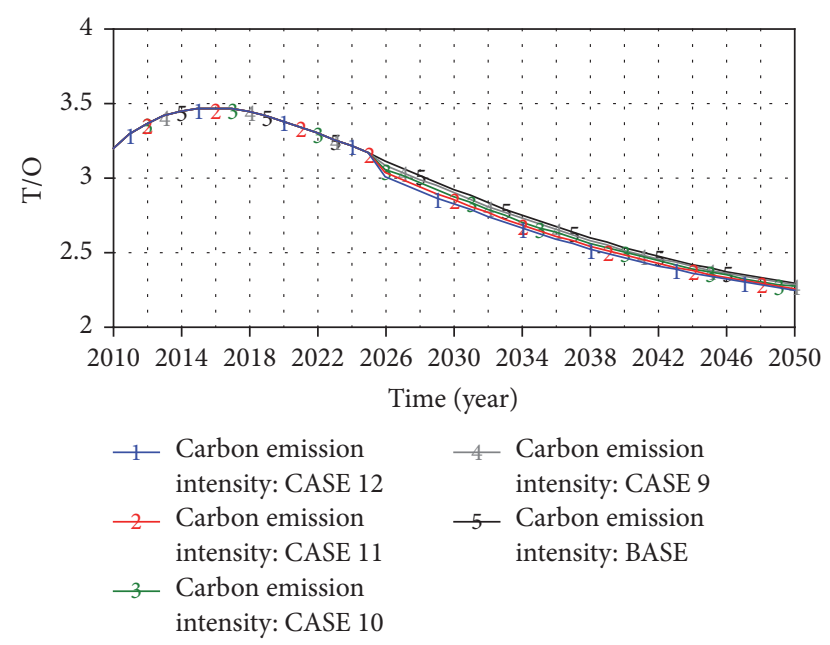

FIgURE 18: The trend of carbon emission intensity under different scenarios (2). The result is under technological progress.

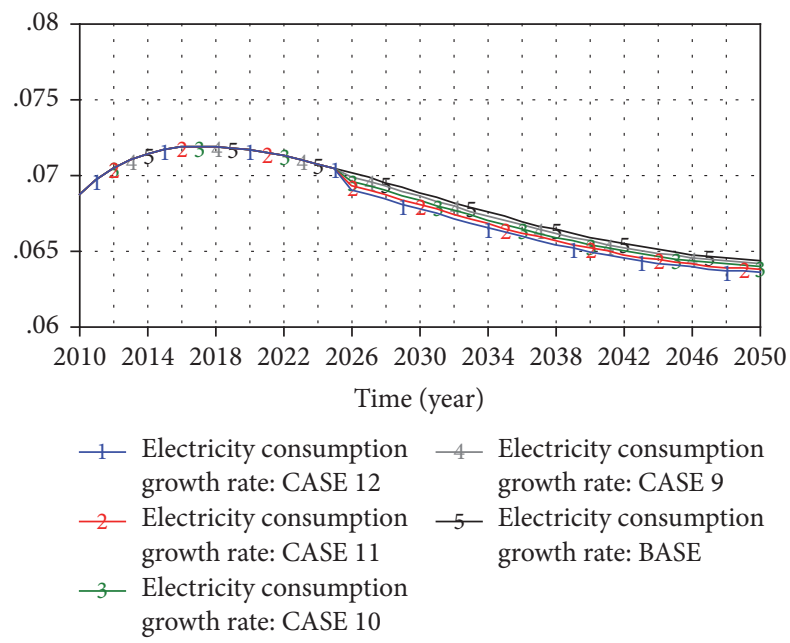

FIGURE 19: The trend of electricity consumption growth rate under different scenarios (3). The result is under technological progress.

consumption growth, it can effectively inhibit the growth of the carbon emissions in power industry.

3.4. Sensitivity Analysis. Through the sensitivity analysis for the key factors of carbon emission reduction in power industry, the carbon emission reduction effect of adjusting technological progress is the most obvious, the adjustment of generation structure takes second place, and the adjustment of carbon intension is the worst, which may even increase carbon emissions. The emission reduction effect of three key factors was shown in Figure 20. It can be seen from the figure that, among them, the effect of technological progress is the best (can be up to $60 \%$ ); the effect of generation structure is second (can be up to $32 \%$ ); the effect of carbon intension is the worst (can increase carbon emission up to $41 \%$ ).

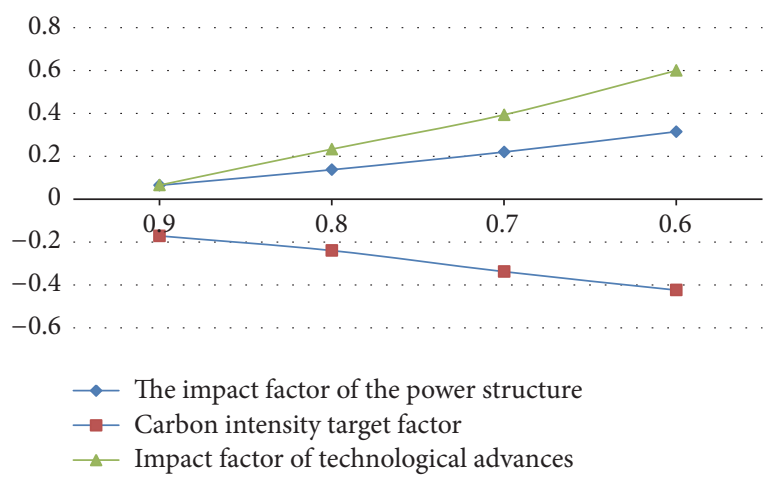

FIGURE 20: The trend of emission reduction factor sensitivity results.

\section{Conclusions and Suggestions}

Through building carbon reduction potential analysis model in power industry, this paper discusses the effectiveness of the carbon market feedback mechanism on power market, conducts the sensitivity analysis for the key factors of carbon emission reduction, and draws the following conclusions.

(1) Through running the system under the baseline scenario, the results show that the feedback mechanism constructed in this paper plays a certain role in suppressing the increase of carbon emissions in power industry, and it can be seen that there is a lag in the carbon emission feedback mechanism; from the long-term carbon emission situation, the carbon emission reduction effect in power industry is obvious.

(2) Through the sensitivity analysis of the generation structure factor, the results show that, on the basis of the carbon emission reduction feedback mechanism constructed in this paper, the adjustment of generation structure can play a better role in reducing carbon emissions, and in the best case it can reduce $32 \%$ of carbon emissions in power industry.

(3) Through the sensitivity analysis of the carbon emission intensity factor, the results show that, on the basis of the carbon emission reduction feedback mechanism constructed in this paper, the reduction of the carbon emission intensity cannot play a role in reducing carbon emissions; on the contrary, due to the increase of electricity consumption growth rate, it will lead to the increase of carbon emissions.

(4) Through the sensitivity analysis of technological progress factor, the results show that, on the basis of the carbon emission reduction feedback mechanism constructed in this paper, the improvement of technological progress level can largely realize the carbon emission reduction goal, and in the best case it can reduce $60 \%$ of carbon emissions in power industry.

\section{Nomenclature}

\section{Symbols}

T: Total value

$\xi$ : Birth or death rate

$\alpha$ : GDP growth rate

$\beta$ : Electricity consumption growth rate 
$\chi$ : Power demand elasticity coefficient

$\varepsilon$ : Error coefficient of fitting function

$C$ : Consumption

$\phi$ : Proportion of thermal power

$\delta$ : The proportion of each energy

$\eta$ : Power generation structure impact factors

$\kappa$ : Proportion parameters of each energy

๗: Weighted coefficient

$e$ : Emission intensity

$o$ : The desired value of thermal power generation proportion

$\rho$ : The difference between actual carbon emission and desired value

$\gamma$ : Delay coefficient

$E$ : Carbon emissions in power industry

$\mu$ : Carbon emissions coefficient

I: Total carbon emissions

$O$ : Target value.

\section{Acronyms}

$. K: \quad K$ time node

.J: $\quad J$ time node

$D: \quad$ Time period from $J$ to $K$

$\Delta: \quad$ The amount of change

DELAY1: Delay function

INTEG: Integral function.

\section{Conflicts of Interest}

The authors declare that there are no conflicts of interest.

\section{Acknowledgments}

This paper is supported by the Fundamental Research Funds for the Central Universities (2016XS82), the National Natural Science Foundation of China (Grants nos. 71273090 and 71573084), and the Beijing Municipal Social Science Foundation (16JDYJB044).

\section{References}

[1] W. Sufeng, Research on Allocation of Carbon Emission Rights and Abatement Mechanism for China, Hefei University of Technology, Anhui, China, 2014.

[2] Y. Li and Y. Yu, "The use of freight apps in road freight transport for $\mathrm{CO}_{2}$ reduction," European Transport Research Review, vol. 9, no. 3, 2017.

[3] S.-m. Yu and L. Zhu, "Impact of firms' observation network on the carbon market," Energies, vol. 10, no. 8, 2017.

[4] B. Koo, "Preparing hydropower projects for the post-paris regime: an econometric analysis of the main drivers for registration in the clean development mechanism," Renewable \& Sustainable Energy Reviews, vol. 73, pp. 868-877, 2017.

[5] A. C. Pigou, Wealth and Welfare, Macmillan and collimated, New York, NY, USA, 1912.

[6] T. D. Crocker, "The structuring of atmospheric pollution control systems," The Economics of Air Pollution, pp. 61-86, 1966.
[7] R. W. Hahn, "Market power and transferable property rights," The Quarterly Journal of Economics, vol. 99, no. 4, pp. 753-765, 1984.

[8] S. Felder and R. Schleiniger, "Environmental tax reform: eficiency and political feasibility," Ecological Economics, vol. 42, no. 1, pp. 107-116, 2002.

[9] T. H. Edwards and J. P. Hutton, "Allocation of carbon permits within a country: a general equilibrium analysis of the United Kingdom," Energy Economics, vol. 23, no. 4, pp. 371-836, 2001.

[10] L. Shoude and H. Tongcheng, "A multi-objectives decision model of initial emission permits allocation," Chinese Journal of Management Science, vol. 11, no. 6, pp. 40-44, 2003.

[11] Z. Wenhui, "The review of initial emission permits allocation theory," Industrial Technology and Economy, vol. 27, no. 8, pp. 111-113, 2008.

[12] L. Changsheng, F. Ying, and Z. Lei, "The study of carbon dioxide emission intensity abatement mechanism of iron and steel industry based on two-stage game model," Chinese Journal of Management Science, vol. 20, no. 2, pp. 93-101, 2012.

[13] W. Chen and F. Teng, "International cooperation mechanisms for carbon reduction," Journal of Tsinghua University (Science and Technology), vol. 45, no. 6, pp. 854-857, 2005.

[14] J. Wu, Z. Kang, and N. Zhang, "Carbon emission reduction potentials under different polices in Chinese cities: a scenariobased analysis," Journal of Cleaner Production, vol. 161, pp. 12261236, 2017.

[15] L.-t. Wong, K.-w. Mui, and Y. Zhou, "Carbon dioxide reduction targets of hot water showers for people in Hong Kong," Water, vol. 9, no. 8, p. 576, 2017.

[16] Y. Yang, W. Qiu, and D. He, "Carbon abatement game between regulator and firms under command-and-control scheme," Systems Engineering, vol. 30, no. 2, pp. 110-114, 2012.

[17] J. Zhou and Y. Diandian, "Studies on provincial differences, influential factors and reduction mechanisms of China's carbon dioxide emission," Shanghai Journal of Economics, vol. 11, pp. 65-80, 2012.

[18] L. Yalu, System Dynamics Model on the Urban Low-Carbon Development Process, Tianjin University, Tianjin, China, 2012.

[19] Y. Chao, Study on Cost Optimization Models of Power Generation's Energy Consumption and Emission under Different Emission Mechanisms, North China Electric Power University, Beijing, China, 2012.

[20] Y. Liu, L. Han, Z. Yin, and K. Luo, "A competitive carbon emissions scheme with hybrid fiscal incentives: The evidence from a taxi industry," Energy Policy, vol. 102, pp. 414-422, 2017.

[21] S. Zeng, X. Nan, C. Liu, and J. Chen, "The response of the Beijing carbon emissions allowance price (BJC) to macroeconomic and energy price indices," Energy Policy, vol. 106, pp. 111-121, 2017.

[22] R. J. Plevin, M. A. Delucchi, and M. O'Hare, "Fuel carbon intensity standards may not mitigate climate change," Energy Policy, vol. 105, pp. 93-97, 2017.

[23] Z. Wang, J. Zhao, and M. Li, "Analysis and optimization of carbon trading mechanism for renewable energy application in buildings," Renewable \& Sustainable Energy Reviews, vol. 73, pp. 435-451, 2017.

[24] S. Ghosh, "Electricity supply, employment and real GDP in India: evidence from cointegration and Granger-causality tests," Energy Policy, vol. 37, no. 8, pp. 2926-2929, 2009.

[25] Y. Liu, X. Hu, and K. Feng, "Economic and environmental implications of raising China's emission standard for thermal power plants: an environmentally extended CGE analysis," Resources, Conservation \& Recycling, vol. 121, pp. 64-72, 2017. 
[26] L. Preusser, "Development of a thermal model for a heated steering wheel to compensate defective feedback variables," in Proceedings of the WCX ${ }^{\mathrm{TM}}$ 17: SAE World Congress Experience, 2017.

[27] K. Safarzyńska and J. C. van den Bergh, "Financial stability at risk due to investing rapidly in renewable energy," Energy Policy, vol. 108, pp. 12-20, 2017. 


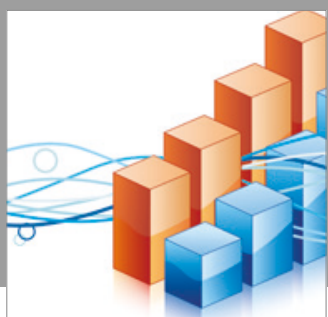

Advances in

Operations Research

vatersals

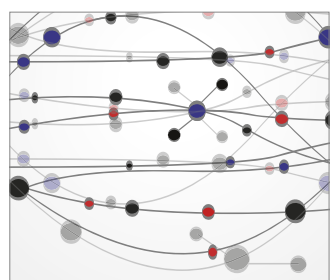

\section{The Scientific} World Journal
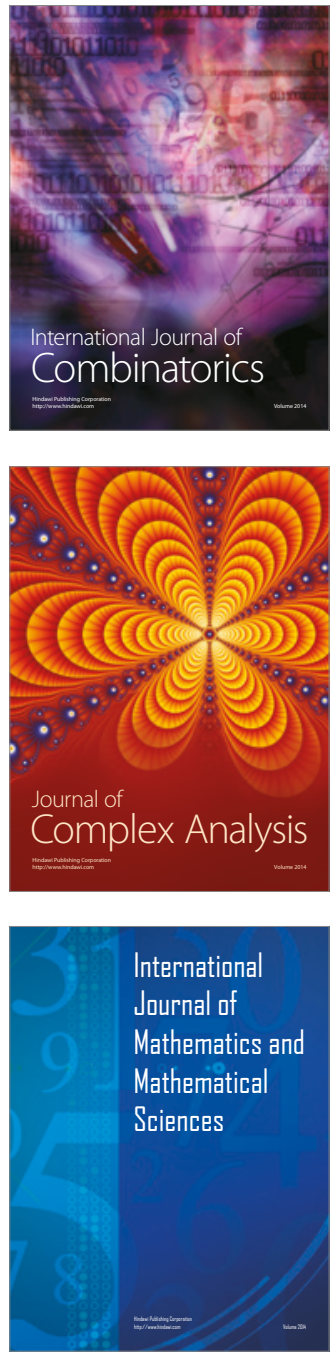
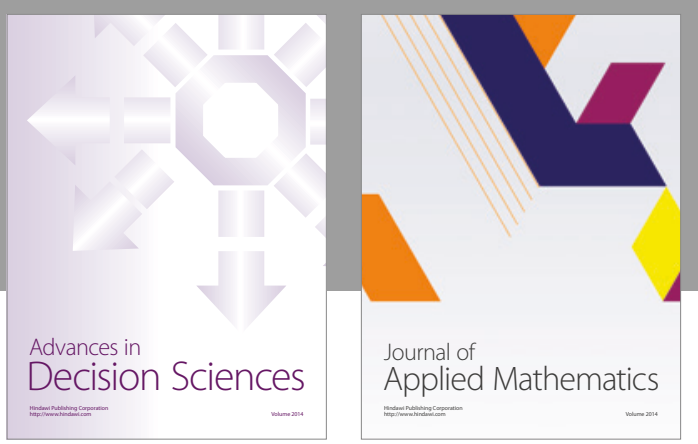

Algebra

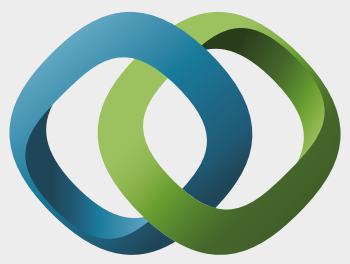

\section{Hindawi}

Submit your manuscripts at

https://www.hindawi.com
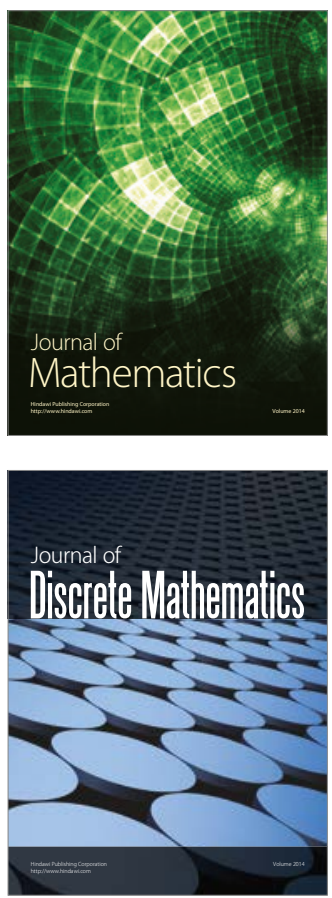

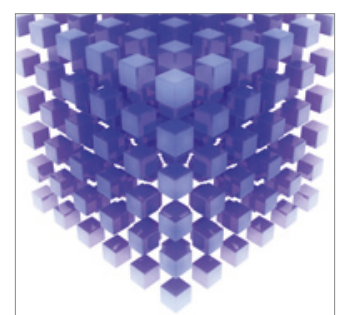

Mathematical Problems in Engineering
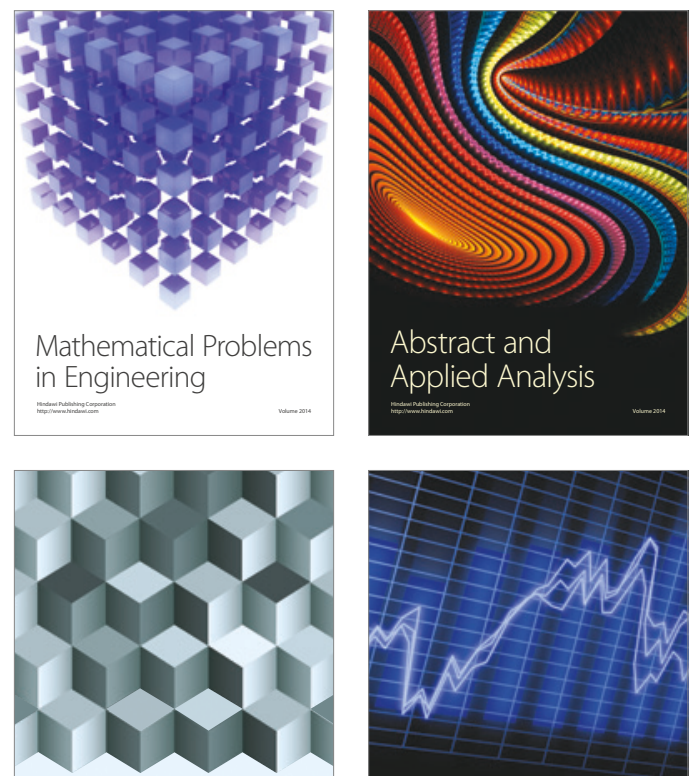

Journal of

Function Spaces

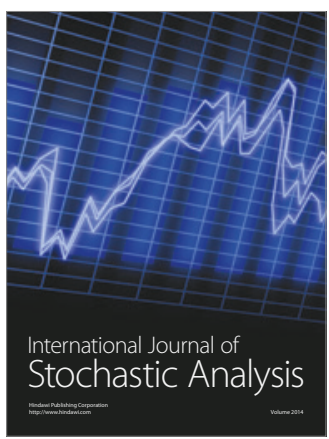

Probability and Statistics
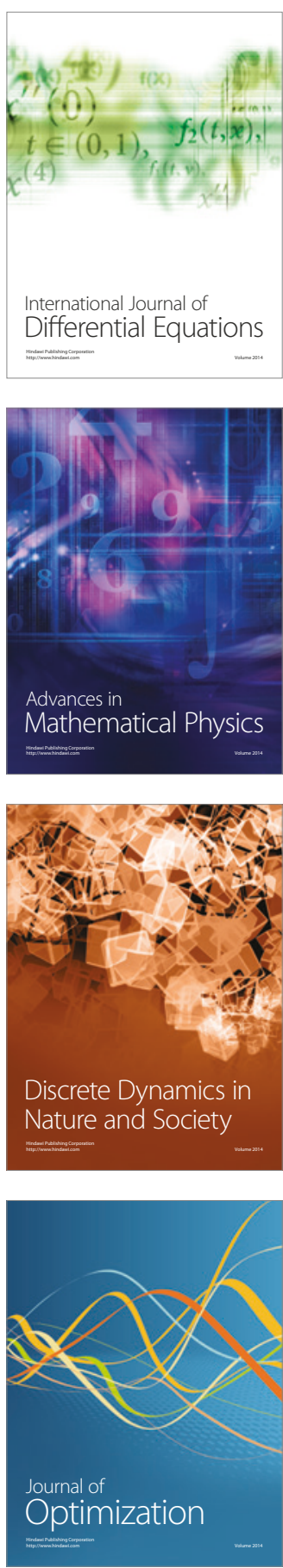